\title{
Patterns of lacrimal dysfunction in primary biliary cirrhosis
}

\author{
A GIOVANNINI,' G BALLARDINI, ${ }^{2}$ S AMATETTI,' P BONAZZOLI,' \\ AND F B BIANCHI
}

From the 'Istituto di Clinica Oculistica I and the ${ }^{2}$ Istituto di Patologia Speciale Medica e Metodologia Clinica I, Università degli Studi di Bologna, Italy

SUMMARY The lacrimal function has been evaluated in 23 patients suffering from primary biliary cirrhosis by rose bengal test, the Schirmer test 1 , and the tear breakup time. Ocular dryness was present in $78 \%$ of cases studied. No difference was found with respect to the length or severity of the hepatic involvement between patients with and without lacrimal dysfunction, but in patients with signs of hypolacrimation the changes in the lacrimal tests increased with the duration and histological progression of liver disease.

Primary biliary cirrhosis (PBC) is a chronic cholestatic disease. It is characterised by granulomatous infiltration of portal tracts with destruction of intrahepatic bile ducts. ${ }^{\prime}$ It is associated with a variety of immunological abnormalities. Among them are a close association with M2-antimitochondrial antibodies, ${ }^{2}$ found in nearly $90 \%$ of cases, alterations of cell mediated immune functions, and increased serum IgM immunoglobulins. ${ }^{3}$ Recently an aberrant expression of HLA-DR antigens on bile duct epithelium has been demonstrated. ${ }^{4}$ Besides the biliary ducts the lacrimal, salivary, and pancreatic ducts may also be involved, thus presenting the picture of a 'dry gland syndrome'. PBC should therefore be regarded as a systemic disease rather than a disorder confined to the liver. The involvement of different organs may induce a variety of clinical pictures, whose common denominator is the presence of chronic liver disease.

The frequent occurrence of ocular dryness ${ }^{6-9}$ has led us to study the presence of possible correlation between lacrimal dysfunction and the histopathological stage, serological parameters, and duration of liver disease.

\section{Material and methods}

Twenty-three patients ( 21 females) ranging in age from 42 to 75 years were studied. The disease

Correspondence to Professor A Giovannini, Istituto di Clinica Oculistica I, Policlinico S. Orsola, Via Massarenti 9, 40138 Bologna, Italy. duration varied from 1 to 15 years. The patients showed typical biochemical changes (Table 1); all of them were positive for antimitochondrial antibodies (AMA) and had a liver histology (biopsy and/or laparoscopy) supporting the diagnosis of PBC.

The patients had no significant eye disorders other than eye dryness, and on the basis of the American Rheumatism Association criteria none of them had osteoarticular symptoms or signs suggesting the diagnosis of rheumatoid arthritis.

The liver biopsy findings were classified in four stages according to accepted criteria. ${ }^{10}$

The ophthalmological investigations included the following,

(1) A history with particular emphasis on conjunctival-lacrimal symptoms.

(2) Biomicroscopic analysis of the anterior and posterior segments.

(3) Tear breakup time (BUT): values lower than 10 seconds are generally considered suggestive of an early rupture of the precorneal film."

(4) Rose bengal test. We referred to Van Bijsterveld's "classification ${ }^{12}$ to assess the severity of the corneoconjunctival epitheliopathy (four stages with increasing severity: degree $0=$ no impregnation, degree $1=$ low impregnation, degree $2=$ medium impregnation, degree $3=$ high impregnation) and to indicate the site (arabic numerals 1,2, and 3 ) for temporal bulbar conjunctival, nasal bulbar conjunctival, and corneal, respectively. The rose bengal test was considered positive when a degree 1 epitheliopathy was present in at least two corneocon- 
Table 1 Biochemical parameters of 23 PBC patients

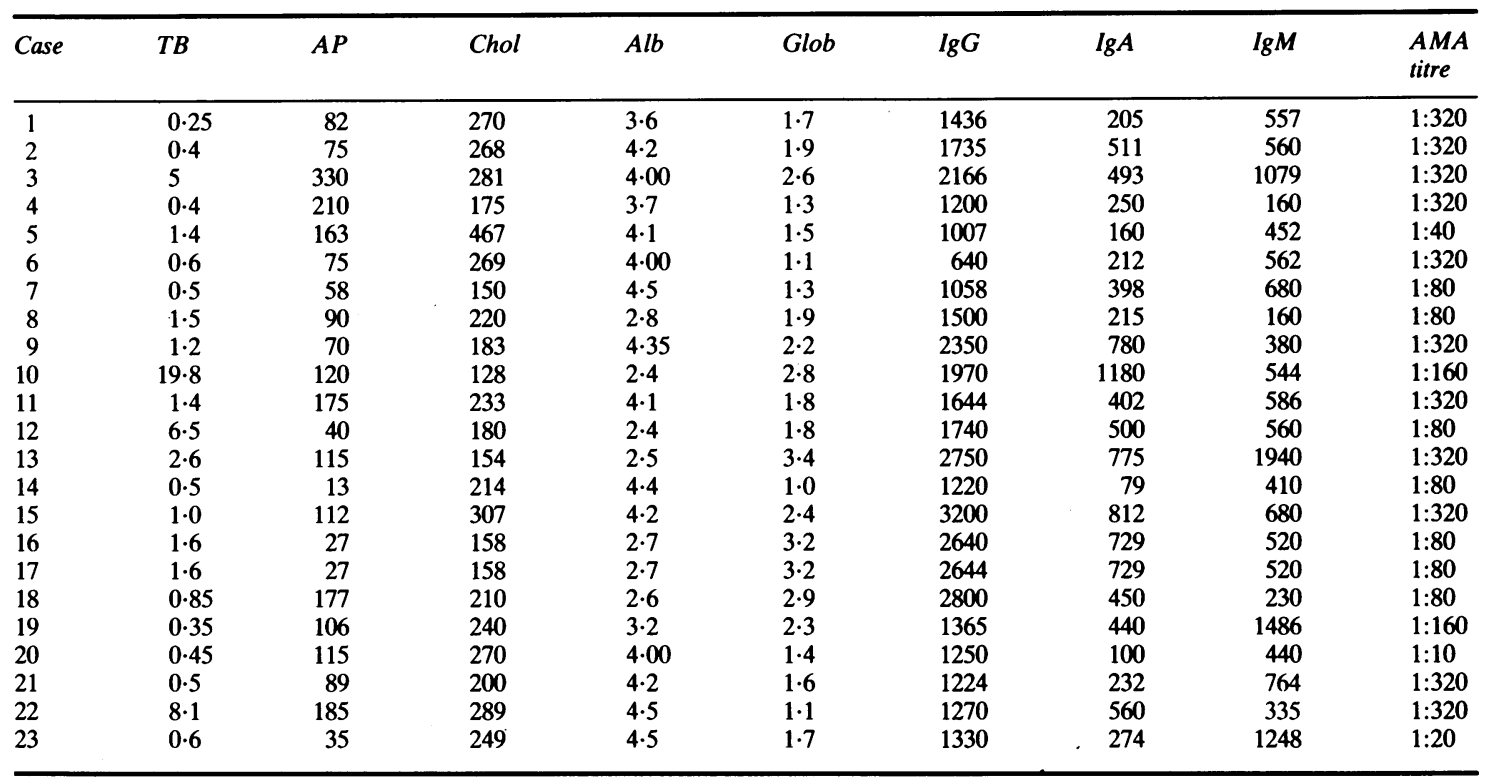

TB = total bilirubin (normal $1 \mathrm{mg} / \mathrm{dl}) . \mathrm{AP}=$ alkaline phosphatase (normal 12-30 mU/ml). Chol=cholesterol (mormal $150-250 \mathrm{mg} / \mathrm{dl}$ ). $\mathrm{Alb}=$ albumin (normal 3·6-4.3 g/dl). Glob=gammaglobulins (normal $1 \cdot 1-1 \cdot 4 \mathrm{~g} / \mathrm{dl}$ ). IgG normal range=420-1450 mg/dl IgA normal range $=60-480 \mathrm{mg} / \mathrm{dl}$. IgM normal $\mathrm{range}=50-390 \mathrm{mg} / \mathrm{dl}$.

SI conversion. TB $\mathrm{mg} / \mathrm{dl} \times 17 \cdot 1=\mu \mathrm{mol} / \mathrm{l}$. Chol $\mathrm{mg} / \mathrm{dl} \times 0 \cdot 0259=\mathrm{mol} / 1$. Alb and $\mathrm{Glob} \mathrm{g} / \mathrm{dl} \times 10=\mathrm{g} / \mathrm{l} . \mathrm{Ig} \mathrm{mg} / \mathrm{dl} \times \mathrm{mg} / \mathrm{l}$.

junctival zones. The data reported in Table 2 represent the mean value of the two eyes.

Tests 3 and 4 are not affected by the age of the patients.
(5) Schirmer's tests 1. Each patients was tested by using blotting paper strips $5 \mathrm{~mm}$ wide and $55 \mathrm{~mm}$ long (blue Carlo Erba litmus paper) inserted $5 \mathrm{~mm}$ down from the temporal side of the inferior fornix. The test

Table 2 Relation between clinical data and lacrimal function in 23 PBC patients

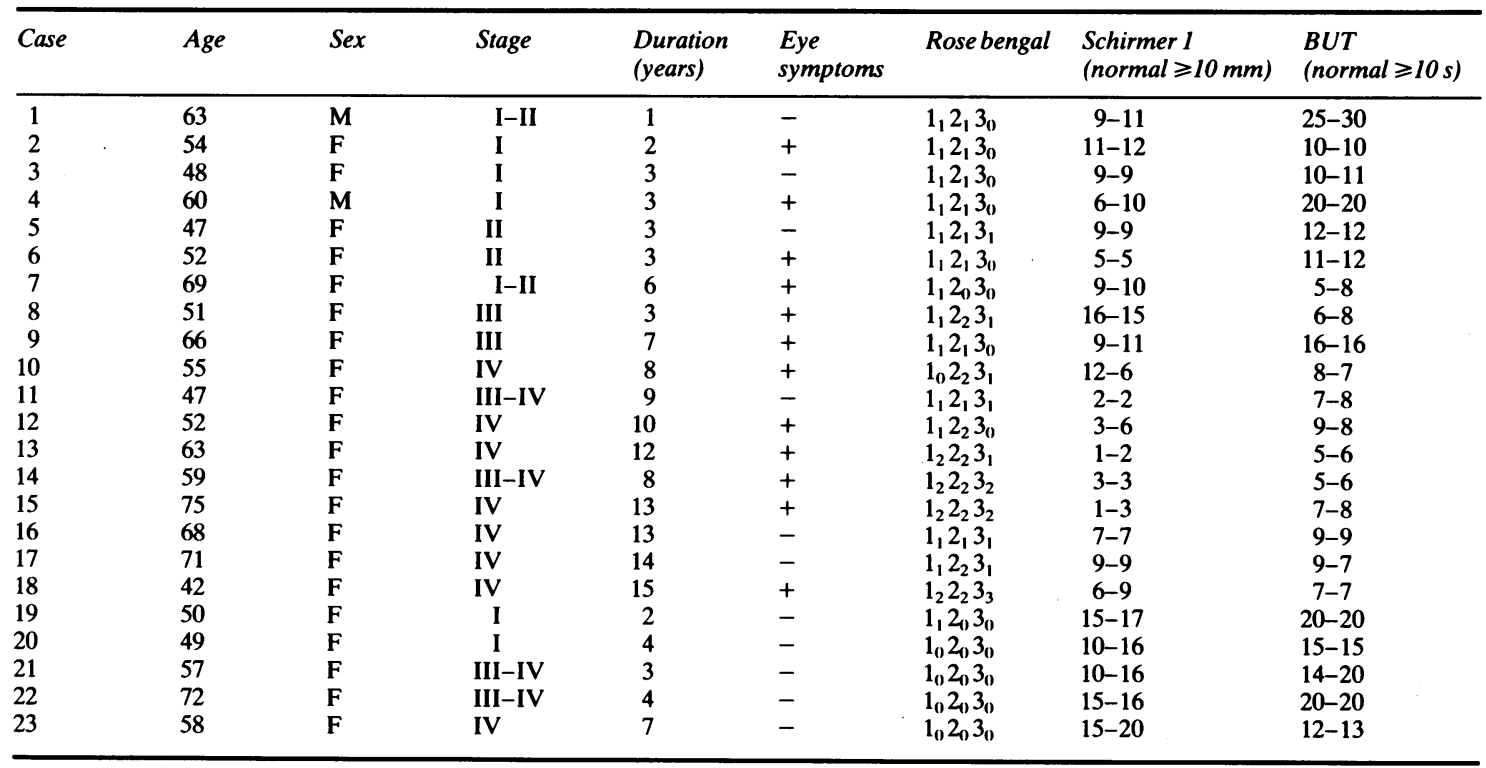


was performed with open lids, with the patients' eyes turned upwards. As Schirmer's test 1 is affected by age $^{13-15}$ in subjects under 60 years, only values lower than $10 \mathrm{~mm}$ after 5 minutes were regarded as suggestive of hypolacrimation.

\section{Results}

The results in each patient are reported in Table 2, as well as age, histological stage, duration (in years) of the disease, and the presence of ocular symptoms suggestive of eye dryness.

Twelve patients $(52 \%)$ had symptoms of ocular dryness, all of them lacrimal dysfunction. Functional changes without symptoms were observed in a further six patients. Thus 18 patients $(78 \%)$ gave abnormal results in the lacrimal tests. In particular the rose bengal test was positive in 17 cases $(74 \%)$, the Schirmer's test in $12(52 \%)$, and the BUT was reduced in $11(48 \%)$. The results of the Schirmer's test 1 in cases $1,7,9,17$, were not regarded as positive because of the age of the patients $(63,69,66,71$ years respectively).

As to the relation between the results of lacrimal tests and liver histology, Table 2 shows that simultaneous positive results of the three lacrimal tests were never found in 9 patients with stages I and II PBC, and two early cases had a normal lacrimal function. Simultaneous positive results of the three tests were found in eight out of 14 patients with stages III-IV PBC, while three patients showed no eye disorder at all.

No correlation between AMA titre, serum IgM levels, and the presence or degree of ocular dryness was found.

The relation between lacrimal function tests and the duration of disease in the 15 patients with altered lacrimal function is shown in Table 2 . The rose bengal test was clearly the first to be altered, followed by Schirmer's test 1 and the BUT test. In eight of the nine stage III-IV PBC patients with a duration of disease of 8-15 years all the tests were simultaneously altered.

\section{Discussion}

As was expected, lacrimal function tests are more sensitive than ocular symptoms in the detection of lacrimal dryness. From the above data it appears that patients suffering from PBC can be divided in two groups: the first comprises a small number of patients with different stages of the disease who do not show any lacrimal disorder; the second group, which is larger $(78 \%)$, comprises patients with a progressive increase of lacrimal dysfunction; the positivity of the rose bengal test appears first, and it is followed by the
Schirmer's test 1 and the BUT test. The number of tests positive in the individual patient and the number of patients positive for all three tests progressively increases in relation to the duration of the disease.

The prevalence of lacrimal changes observed in our patients $(78 \%)$ is in agreement with the data of Golding et al. (72\%), ${ }^{7}$ McFarlane et al. $(69 \%),{ }^{8}$ and Alarcon-Segovia et al. (71\%). ${ }^{9}$ Alarcon-Segovia and colleagues reported in detail the results obtained in 14 patients with PBC. In the cases with keratoconjunctivitis sicca $(71 \%)$ they found no relation either with the histological stage or with the duration of the liver disease, which was shorter than that of the present series (1-6 years compared with 1-15 years). In their study the lacrimal function was examined by the rose bengal test and the Schirmer's test 1, which was considered positive if moistening of the strip was less than $5 \mathrm{~mm}$; the BUT test was not performed.

The interpretation of the results obtained by the Schirmer's test 1 is still debated because various factors can considerably affect tear formation. In a recent study performed on 100 normal subjects an average tear production of $19 \mathrm{~mm}^{13}$ was found; men older than 55 years and women older than 60 years have a lower tear production, so that at ages between 70 and 80 years values lower than $5 \mathrm{~mm}$ were commonly observed in subjects without eye disorders. ${ }^{14}$ Consequently one may question the interpretation of the negative findings (Schirmer's test 1 values less than $5 \mathrm{~mm}$ ) given by AlarconSegovia et al. ${ }^{9}$ for three patients with ages between 45 and 62 years who had been suffering from liver disease for 5-6 years. If on the contrary the limiting value of this test is fixed at $10 \mathrm{~mm}$, these observations could be interpreted as confirmatory of our results.

In conclusion, most $\mathrm{PBC}$ patients seem to acquire the sicca syndrome. No clear-cut differences in duration or severity of liver disease are seen between patients with and without lacrimal disorders. Since the subgroup of PBC without ocular-lacrimal involvement comprises patients with a long disease duration and an advanced histological stage, it is conceivable that they will never have eye disorders. On the contrary, most patients develop lacrimal dysfunction in the early stages of the disease, starting with slight positivity of the rose bengal test and followed by progressively positive results from the other tests.

It is now known that the primary and secondary sicca syndromes (as observed in PBC) are distinct diseases, since they are associated with different immunological markers. ${ }^{\text {th }}$ While primary sicca syndrome is linked to HLA-B8,DR3 haplotypes, no such relation has been found in secondary sicca syndrome. ${ }^{17}$

Whether lacrimal dysfunction in PBC is related to 
the same immunological mechanism responsible for biliary destruction remains to be clarified.

\section{References}

1 Sherlock S. Diseases of the liver and biliary system. London: Blackwell, 1981.

2 Munoz LE, Thomas HC, Scheuer PJ. Is mitochondrial antibody diagnostic of primary biliary cirrhosis? Gut 1981; 22: 136-40.

3 James SP, Hoofnagle JH, Strober W, Jones EA. Primary biliary cirrhosis: a model of autoimmune disease. Ann Intern Med 1983; 99: 500-12.

4 Ballardini G, Mirakian R, Bianchi FB, Pisi E, Doniach D, Bottazzo GF. Aberrant expression of HLA-DR antigens on bile duct epithelium in primary biliary cirrhosis: relevance to pathogenesis. Lancet 1984; ii: 1009-13.

5 Epstein $\mathrm{O}$, Thomas HC, Sherlock S. Primary biliary cirrhosis is a dry-gland syndrome with features of chronic graft-versus-host (GVH). Lancet 1980; i: 1166-8.

6 Whaley K, Williamson J, Dick WC, Goudie RB, Nuki G, Buchanan WW. Liver disease in Sjögren's syndrome and rheumatoid arthritis. Lancet 1970; i: 861-3.

7 Golding PL, Bowh R, Mason AMS. Sicca complex in liver disease. Br Med J 1970; iv: 340-2.
8 McFarlane IG, Wojcicke BM, Tsantoulas DC, et al.Cellular immune responses to salivary antigens in autoimmune liver disease with sicca syndrome. Clin Exp Immunol 1976; 25: 389-95.

9 Alarcon-Segovia DMD, Diaz J, Fishbein E. Features of Sjögren syndrome in primary biliary cirrhosis. Ann Intern Med 1973; 79: 31-6.

10 Scheuer PJ. Liver biopsy interpretation. Baltimore: Williams and Wilkins, 1973.

11 Rojer J, Adenis JP, Bernard JA, Metaireau JP, Renj A. L'appareil lacrimale. Paris: Masson, 1982.

12 Van Bijsterveld OP. Diagnostic tests in the sicca syndrome. Arch Ophthalmol 1969; 82: 10-4.

13 Arrata M, Leroux-les-Jardins S, Cummings S, Wilson S. Valeurs normales des tests de la sécrétion lacrymale. Bull Mem Soc Fr Ophtalmol 1983; 94: 23-9.

14 Henderson JW, Prough WA. Influence of age and sex on flow of tears. Arch Ophthalmol 1950; 43: 224-31.

15 Veirs ER. Lacrimal disorders, diagnosis and treatment. St Louis: Mosby, 1976: 23-36.

16 Tan EM. Autoantibodies to nuclear antigens (ANA): their immunobiology and medicine. Adv Immunol 1982; 33: 167-240.

17 Motsopoulos HM, Mann DL, Johonson H, Chused TM. Genetic differences between primary and secondary sicca syndrome. N Engl J Med 1979; 301: 761-3. 